\title{
Effects of Female Genital Mutilation on the Girl Child's Physical Health among Ameru Community of Kenya
}

\author{
Dr. Susan Muthoni Kinyua \\ Dept. of Education, Chuka University, PO Box 109 - 60400, Chuka, Kenya \\ Email:mobuoush@yahoo.com \\ Dr. Veronica Karimi Nyaga \\ Dept. of Education, Chuka University, Kenya \\ Prof. Micah C. Chepchieng \\ Dept. of Psychology, Counselling and Educational Foundations \\ Egerton University, Kenya \\ Prof. (Fr) Stephen Ngari Mbugua \\ Dept. of Psychology, Counselling and Educational Foundations \\ Egerton University, Kenya
}

Doi:10.5901/ajis.2014.v3n4p189

Abstract

This study sought to determine the effects of Female Genital Mutilation (FGM) on the girl child's physical health among the Ameru community of Kenya. The study employed the descriptive survey research design on a sample comprising of 408 girls who had undergone FGM, 48 health workers, 3 social workers and 30 Focus Group Discussion members selected by use of snow ball sampling and purposive sampling techniques. Data were collected using questionnaires, interview schedules and Focus Group Discussion schedules. The data were analyzed using Statistical Package for Social Sciences version 17.0. Descriptive statistics were used to analyze the data whose findings indicated that FGM negatively affected the physical health of the girl child and in some instances resulted in death. Thus, it was recommended that the government and nongovernmental organizations should enhance interventions on physical health effects of FGM in order to alleviate the sufferings of the girl child among the Ameru community.

Keywords: Female Genital Mutilation, Girl Child, Physical Health

\section{Introduction}

The Ameru community in Kenya practice FGM despite the ban by the Government and the Njuri Ncheke (Supreme Council of Ameru Elders) due to adverse physical health effects the practice has on the girl child. Basically, FGM or female genital cutting also known as clitoridectomy is a traditional practice that involves the partial removal, total removal or alteration of girls' or women's genitalia (WHO, 2006). The practice has existed over a long time among diverse communities in the world (Toubia, 1994) as a traditional rite of passage from childhood to adulthood. In particular, FGM is common in Africa although through immigration and population movements the practice has spread to Europe, North and South America, Australia and New Zealand thus, becoming a worldwide issue (Pillinger, 2007). According to the World Health Organization, it is estimated that about 130 million girls and women living today in the world have undergone the FGM and yet every year another 2 million girls and young women are at risk despite its many adverse consequences (WHO, 2006). Essentially, there are diverse FGM physical health effects experienced by initiated girls. The effects may be immediate including excruciating pain, shock, wound formation, urinary tract infection, fever, septicemia and at times death due to haemorrhage or septic shock; intermediate effects like delay in wound healing, anaemia, pelvic infections, irregular bleeding and vaginal discharge; and eventually late effects such as infertility, difficulty in urinating, rectovaginal fistula, anal incontinence and urinary incontinence (Wabaki, 2007; WHO, 1996). While these effects may not be 
experienced by some initiated girls and that the effects tend to differ from one person to another, there are initiated girls who experience some of the physical health effects on a daily basis (Abusharaf, 2000).

Unfortunately, many initiated girls may be suffering from FGM physical health effects in silence partly because of the cultural explanations of such effects and possibly due to fear of victimization by the authority when medical care is sought from public health facilities. In particular, some cultures rationalize the physical health effects of FGM as part of life and that the initiated girls should persevere for the purpose of preserving personal social identity (Valderman, 2002). Similarly, the Nandi community of Kenya advocate for FGM because the clitoris is culturally perceived as being filthy, foul smelling and can grow very long even develop branches if not cut (Nyangweso, 2001) thus, nullifying the physical health effects of FGM. Besides, in Sierra Leone physical health effects of FGM are attributed to witchcraft, supernatural powers and general bad luck (Taubia, 1999). Therefore, in an attempt to demystify FGM and create awareness of its adverse consequences, this study sought to determine the effects of FGM on the girl child's physical health among Ameru community of Kenya.

\section{Objectives of the Study}

The main objective of this study was to determine the effects of FGM on the girl child's physical health among Ameru community of Kenya.

\section{Methodology}

This study employed the descriptive survey research design targeting a population of 137,044 respondents. A sample comprising of 408 girls who had undergone FGM were selected using snow ball sampling technique while 48 health workers, 3 social workers and 30 Focus Group Discussion members were purposively selected for the study. Data were collected using questionnaires, interview schedules and Focus Group Discussion schedules. Qualitative data were coded and analyzed using Statistical Package for Social Sciences version 17.0 while qualitative data from interviews and focus group discussion were thematically analyzed. Descriptive statistics including frequencies, percentages, means, and standard deviation as well as themes and excerpts were used to analyze the data. The study findings were presented on tables and as prose narrations.

\section{Results and Discussion}

The following are the results and discussions of the study.

\subsection{Demographic Characteristics of the Respondents}

This section focuses on the demographic characteristics of the respondents whose background information is essential in understanding some of the salient features of the study participants.

\subsubsection{Demographic Characteristics of the Initiated Girls}

Demographic analysis of the initiated girls was done on the basis of the respondents' age, residence settings, level of education as well as religious affiliations. The number of initiated girls who participated in the study was 407 of whom 41 initiated girls were aged between 14 years and 19 years, 244 girls between 20 years and 24 years while 122 girls were aged between 25 years and 30 years. Regarding the residence settings, it seems that majority of the initiated girls comprising $90.7 \%$ came from rural areas as opposed to only $9.3 \%$ who came from the urban setup. This observation reflects the general trend where FGM is widely practiced among the rural population (Kanake, 2001). Remote rural areas in most cases are less exposed to formal government services and administrators, and this perhaps encourages the practice of FGM as evidenced by the high number of respondents who have undergone FGM in rural areas. Besides, studies done by DOM-CPJC (2008) suggest that the Ameru girl's rural home is the main place where FGM is carried out. The distribution of the respondents by religious affiliation suggests that majority of the respondents constituting $51.8 \%$ were Protestants; $42.3 \%$ were Catholics and $2.7 \%$ were Muslims. The high percentage of the Christians that is Protestants and Catholics may be attributed to the contribution of the early church missionaries to social development projects such as building of schools, hospitals and churches in most parts of the Ameru community (DOM-CJPC, 2008). 
Nevertheless, the small percentage comprising $2.7 \%$ of girls affiliated to Muslim religion is perhaps a reflection of the small number of people who profess Muslim faith among the Ameru.

\subsubsection{Demographic Characteristics of the Health Workers}

A total of 46 health workers were involved in the study to provide supplementary information on effects of FGM on the girl child's physical health. The distribution of health workers by gender was almost proportional with female health workers making up $54.3 \%$ and the male health workers' percentage being $45.7 \%$. This distribution trend is common in Kenyan health sector where the majority of the medical staff are female. These findings may be attributed to the traditional perception that provision of medical services is a females' occupation. The age distribution of the health workers indicated that $54.3 \%$ of the respondents were between ages 25 years and 34 years; $21.7 \%$ were between ages 35 years and 34 years while $17.4 \%$ were at least 45 years. Regarding work experience, a large proportion constituting $32.6 \%$ of the respondents had an experience of between 5 years and 10 years; $26.1 \%$ of the health workers had work experience of at least 15 years while $28.3 \%$ had worked for less than 5 years.

\subsubsection{Demographic Characteristics of the Social Workers}

The three female social workers involved in the study were from Igembe South District, Tharaka District and Meru South District respectively. The findings also indicated that two of the social workers were above 45 years of age while the third one was aged between 35 years and 44 years. At these ages, the social workers are energetic and mature enough to handle community activities efficiently and also have more community service experiences as well as enough knowledge on FGM issues necessary for this study. In addition, all the social workers had college or university education meaning that these respondents were qualified professionally to comment on FGM related issues for this study.

\subsection{Physical Health Effects of FGM on the Girl Child}

In this study, three Physical Health domains were examined which included Sexual difficulties, Maternal health and Bodily harm and infections. Responses were generated by use of questionnaires, interviews and focus group discussions. The questionnaires were administered to the initiated girls and health workers, interviews were conducted with the social workers while the focus group discussions involved selected community members.

\subsubsection{Girls' Views on Physical Health Effects Related to FGM}

Information sought from the initiated girls on physical health effects related to FGM were analyzed by determining the mean and the standard deviation of 20 items on a 5 point Likert Scale where Strongly Disagree $=1$, Disagree $=2$, Undecided $=3$, Agree $=4$, Strongly Agree $=5$. The information on Table 1 represents the data analysis results.

Table 1. Girls' Views on Physical Health Effects Related to FGM

\begin{tabular}{|l|c|c|c|}
\hline \multicolumn{1}{|c|}{ Sexual Difficulties Related to FGM } & N & M & SD \\
\hline FGM practice has led me into being sexually dysfunctional & 407 & 3.8796 & 1.13074 \\
\hline I experience regrettable sexual memories because of FGM & 407 & 3.6855 & 1.08929 \\
\hline FGM makes me experience painful sexual intercourse & 407 & 3.6216 & 1.16362 \\
\hline FGM caused my genitalia dryness and post-coital bleeding & 407 & 3.2973 & 1.20858 \\
\hline After FGM i experience no sexual arousal & 407 & 3.7125 & 1.24109 \\
\hline FGM has been a limitation to my sexual satisfaction & 407 & 3.9582 & 1.11555 \\
\hline Overall Mean and Standard Deviation on Sexual Difficulties Responses & & 3.7572 & .85453 \\
\hline Maternal Health Issues Related to FGM & & & \\
\hline FGM caused my childbirth complications & 407 & 3.6806 & 1.22422 \\
\hline FGM caused my urinary and menstrual problems & 407 & 3.0147 & 3.30922 \\
\hline I suffer recurrent reproductive tract infections due to FGM & 407 & 3.0762 & 1.11488 \\
\hline FGM contributed to my difficult gynecological examination & 407 & 3.2039 & .98270 \\
\hline After FGM I have limited contraceptive choices & 407 & 2.5381 & 1.07726 \\
\hline FGM caused maternal death to some of my friends. & 407 & 3.4079 & 1.19140 \\
\hline
\end{tabular}




\begin{tabular}{|c|c|c|c|}
\hline Overall Mean and Standard Deviation on Maternal Health Responses & & 3.1536 & 0.78651 \\
\hline \multicolumn{4}{|l|}{ Bodily Harm and Infections Related to FGM } \\
\hline Am worried that FGM may transmit STIs and HIVIAIDS infections to me & 407 & 4.0835 & 1.08182 \\
\hline FGM made me suffer from severe Anaemia & 407 & 3.8280 & 1.06900 \\
\hline FGM exposed me to tetanus infection & 407 & 2.8649 & 1.27264 \\
\hline FGM led to my urethra and bladder damage & 407 & 3.1057 & 1.25205 \\
\hline FGM led to the growth of keloids scars around my genitalia & 407 & 3.8501 & 1.07806 \\
\hline Some of my friends have bleed to death due to FGM & 407 & 3.9975 & .90836 \\
\hline FGM has made me to suffer from painful and blocked menses & 407 & 3.2948 & 1.20408 \\
\hline FGM made me experience urine retention due to pain, swelling and blocked urethra & 407 & 3.2727 & 1.31375 \\
\hline Overall Mean and Standard Deviation on Bodily Harm and Infections Responses & & 3.5372 & 0.80339 \\
\hline
\end{tabular}

Key: M - Mean SD - Standard Deviation N - Number of respondents

The overall mean and standard deviation of initiated girls' responses about sexual difficulties associated with FGM were 3.7572 and 0.85453 respectively out of the maximum mean score of 5 points. This indicates that the initiated girls were moderately prone to experiencing sexual difficulties including dryness and pain during sexual intercourse, not enjoying sex, post coital bleeding and never or rarely experiencing orgasm. Although some of the girls could still have been too young to begin getting into sexual affairs while others may not have associated negative sexual experiences with FGM, many respondents affirmed that FGM had been a limitation to sexual satisfaction, caused sexual dysfunction and negatively interfered with sexual arousal. This finding is in agreement with Njeru \& PATH (2000) studies among Aembu girls; where it was observed that girls who had undergone FGM had limited sexual satisfaction, experienced pain during sexual intercourse and never experienced orgasm. Besides, Nyangweso (2007) confirms that with FGM, parts of the women's erogenous genital areas as well as sexually responsive vascular tissue are removed. This excision of women's genital parts coupled with damaged nerve-endings and the development of scar tissue and adhesions around the excised parts reduce a woman's capacity for sexual enjoyment.

The overall mean and standard deviation of initiated girls' responses about maternal health difficulties were 3.1536 and 0.78651 respectively out of the maximum mean score of 5 points. This depicts that most of the initiated girls were undecided on whether maternal health difficulties were caused by FGM. This is probably because maternal health difficulties may not have been experienced by most of the girls particularly those who had not given birth. Otherwise, majority of the initiated girls as reflected by higher mean scores were of the opinion that FGM caused child birth complications including maternal deaths. These views are supported by Hansen (1972) noting that maternal death in most cases is caused by excessive bleeding from FGM scars which may also precipitate other obstetric complications including prolonged and obstructed labour and bleeding resulting into difficulties in child delivery and sometimes death of the mothers. Mwangi-Powell (1999) also affirms that there are many delivery problems among the FGM women.

The overall mean and standard deviation of initiated girls' responses about bodily harm and infections related to FGM were 3.5372 and 0.80339 respectively out of the maximum mean score of 5 points. This insinuates that the initiated girls experienced moderate bodily harm and infections as a result of FGM. According to Abusharaf ((2000) not everyone who undergoes FGM experiences painful complications and those who do, the complications experienced differ from one person to another. However, many of the initiated girls were worried that FGM would promote transmission of STIs and HIVIAIDS infections to them. This is mainly because of the unhygienic conditions in which the FGM procedures are carried out as indicated by (Barstow, 1998) linking this to transmission of STIs, HIVIAIDS and tetanus infections. Besides, WHO (2006) purports that FGM initiates are prone to transmission of STIs and HIVIAIDS due to bleeding during sexual intercourse as a result of lasting damage to the genital area.

\subsubsection{Health Workers' Views on Physical Health Effects Related to FGM}

Information sought from the girls on physical health effects related to FGM were analyzed by determining the mean and the standard deviation of 20 items on a 5 point Likert Scale where Strongly Disagree $=1$, Disagree $=2$, Undecided $=3$, Agree $=4$, Strongly Agree $=5$. The information on Table 2 represents the data analysis results. 
Table 2. Health Workers' Views on Physical Health Issues Related to FGM

\begin{tabular}{|l|c|c|c|}
\hline \multicolumn{1}{|c|}{ Sexual Difficulties Related to FGM } & N & M & SD \\
\hline FGM practice leads to sexual dysfunction among the girls & 46 & 3.6957 & 1.31436 \\
\hline FGM practice is a source of regrettable sexual memories & 46 & 3.6739 & 1.31748 \\
\hline The practice of FGM results to painful sexual intercourse & 46 & 3.8261 & 1.08124 \\
\hline FGM causes genitalia dryness and post-coital bleeding & 46 & 3.3261 & 1.30050 \\
\hline Girls who have undergone FGM experience no sexual arousal & 46 & 3.8261 & 1.28762 \\
\hline FGM limits a girls' sexual satisfaction & 46 & 4.0000 & 1.11555 \\
\hline Overall Mean and Standard Deviation on Sexual Difficulties Responses & & 3.7836 & 0.96983 \\
\hline \multicolumn{1}{|c|}{ Maternal Health Issues Related to FGM } & & & \\
\hline FGM causes child birth complications & 46 & 4.3913 & .80217 \\
\hline FGM leads to urinary and menstrual problems & 46 & 2.8261 & 1.33840 \\
\hline FGM is a source of recurrent reproductive tract infections & 46 & 2.9565 & 1.19176 \\
\hline FGM results to difficult gynecological examinations & 46 & 3.7609 & 1.28556 \\
\hline FGM limits contraceptive choices & 46 & 2.6087 & 1.4972 \\
\hline FGM is a contributory factor to maternal death & 46 & 3.9130 & 1.13188 \\
\hline Overall Mean and Standard Deviation on Maternal health Issues Responses & & 3.4094 & $\mathbf{0 . 8 5 8 3 0}$ \\
\hline \multicolumn{1}{|c|}{ Bodily Harm and Infections Related to FGM } & & & \\
\hline FGM facilitates transmission of STIs and HIVIAIDS infection & 46 & 4.4130 & .97925 \\
\hline Girls who have undergone FGM suffer from severe aneamia & 46 & 3.6522 & 1.19661 \\
\hline Girls involved in FGM suffer from tetanus & 46 & 2.7609 & 1.09919 \\
\hline FGM damages girl's urethra and bladder & 46 & 3.1522 & 1.29901 \\
\hline FGM leads to growth of keloid scars around the genitalia & 46 & 3.8261 & 1.30477 \\
\hline FGM excessive bleeding and infected wounds often cause death & 46 & 4.2174 & .84098 \\
\hline FGM causes urine retention due to pain, swelling and blocked urethra & 46 & 3.2727 & 1.31375 \\
\hline FGM results to painful or blocked menses & 46 & 2.8478 & 1.36573 \\
\hline Overall Mean and Standard Deviation on Bodily Harm and Infections Responses & & 3.4946 & $\mathbf{0 . 7 8 8 7 9}$ \\
\hline
\end{tabular}

Key: M - Mean SD - Standard Deviation N - Number of respondents

The overall mean of the health workers' responses regarding Sexual difficulties experienced by initiated girls was 3.7826 with a standard deviation of 0.96983 out of the maximum mean scores of 5 points. This implies that the girls experienced moderate sexual difficulties after undergoing FGM process; a response that supports the initiated girls' responses. This suggests that the health workers were in agreement that FGM limits a girl's sexual satisfaction and sexual arousal as well as causing genitalia dryness, post coital bleeding and regrettable sexual memories. Indeed, FGM causes permanent, irreparable changes in the external female genitalia potentially disrupting its sexual functioning (WHO, 2000). In line with these findings, Nyangweso (2007) affirms that the mutilation of the clitoris during FGM is believed to reduce a woman's desire for sex, sexual pleasure and orgasm during intercourse. In addition, Einstein (2008) notes that with FGM, some fundamental structures for sexual stimulation and orgasm are excised leading to immediate sexual consequences such as pain during intercourse, lack of sexual satisfaction, never experiencing orgasm, no arousal during intercourse and post coital bleeding.

The health workers' responses' mean on maternal health difficulties related to FGM was 3.4094 with a standard deviation of 0.85830 out of the maximum mean score of 5 points. This suggests that the maternal health of the initiated girls is moderately affected by FGM. The findings on Table 2 indicate that initiated girls experienced maternal health difficulties especially with regard to child birth complications, maternal deaths and difficulty in gynecological examination. In agreement with these results, Abor (2006) asserts that FGM affects the maternal well being of a girl because the female genitalia is deformed making it difficult for the baby to pass through. Therefore, caesarian sections mode of delivery is preferred to avert the problems associated with the risks of excessive bleeding due to lacerations and tears at the genital area and excessive pain associated with the scared tissue. In addition, Toubia (1999) explains that after episiotomies, because the structures are not normal, the initiated girls experience excessive bleeding that may lead to anaemia and eventually death.

The overall mean of the health workers' responses on bodily harm and infections experienced by initiated girls was 3.4946 with a standard deviation of 0.78879 out of the maximum mean score of 5 points. This indicated that the health workers were undecided whether FGM actually caused bodily harm and infections. However, the higher mean scores indicated that initiated girls suffered sexually transmitted infections including HIVIAIDS as a result of FGM. Moreover, 
excessive bleeding and infected wounds were deemed as causing anaemia and even death among the initiated girls. In addition, the initiated girls developed keloid scars around the genitalia. Technically, it may be inferred that the lack of strong evidence for existence of tetanus and problems with menses related to FGM could have been due to failure by the initiated girls to seek medical attention thus, hindering the health workers from keeping any records of such cases. In retrospect, Taubia (1999) observes that FGM complications may be attributed to witchcraft, supernatural powers and general bad luck. As a result, the initiated girls may not seek medical care intervention for the bodily harm and infections.

\subsubsection{Social Workers' Views on Physical Health Effects Related to FGM}

The social workers were asked to expound on the physical health effects of FGM on girls who underwent the procedure. The participants highlighted sexual difficulty issues as tearing, bleeding and pain during sexual intercourse, limited sexual desire as well as impaired sexual responses. These findings support the idea that removal of clitoris and other sensual organs may decrease a woman's sexual desire and dampen sexual responses (Einstein, 2008). Incidentally, these sexual difficulties were purported by social workers as generating marital problems such as infidelity, quarrels, communication breakdown as well as divorce.

According to the views of social workers, the maternal difficulties associated with FGM emerged as complicated child birth and inability to use some contraceptives. In particular, a certain participant stated "even during child birth, initiated girls prefer traditional birth attendants who may not have the skills and facilities to negotiate complicated deliveries. This may increase the risk of further maternal health complications and death as well". In agreement with this finding, Abor (2006) postulates that deformity of the genitalia due to FGM contributes to difficult child birth. Thus, there is need for the government and non governmental institutions to intervene either by educating the traditional birth attendants or availing special user friendly maternal facilities for the initiated girls in order to curb unnecessary maternal health complications and deaths.

Bodily harm and infections prevalent among FGM initiates according to social workers included: scaring of the genitalia, fainting especially immediately after the procedure due to excruciating pain, excessive bleeding often leading to anaemia or sometimes death and the risk of HIVIAIDS infection. These findings confirm that initiated girls are more likely to suffer from sexually transmitted infections and related infections (WHO, 2006). Besides, with regard to tendencies of seeking medical attention by the initiated girls, the social workers were of the opinion that traditional healers received most of the cases generally because of the fear of government authority and lack of funds to visit private health facilities. Thus, treatment was mostly by use of traditional herbal medicine meaning that majority of the initiates had to bear lengthy periods of pain and discomfort.

\subsubsection{Focus Group Discussion Members' Views on Physical Health Effects Related to FGM}

The focus group discussions had various views regarding physical health effects of FGM on initiated girls. Concerning sexual difficulties experienced by the initiated girls, issues of bleeding during and after sexual encounters, pain during sex, decreased sexual arousal and lack of sexual pleasure were raised. The following excerpt pertains a response from a certain participant, "pain and bleeding during sex is as a result of the narrowing vaginal opening due to FGM. Consequently, serious marital relationship conflicts emerge." In essence, marriages involving initiated girls called for patience and understanding by a spouse in order to avert disagreements, conflicts or even divorce. In addition, another participant stated, "The vaginal opening can narrow until it almost closes up. Such initiated girls must be opened up either surgically or through penetrative sex. This means that sexual intercourse especially in the first months of marriage is usually painful for the initiated girls." Aside from the removal of clitoris (the source of sexual pleasure), the pain experienced during sex impaired sexual responses and pleasure causing many of the initiated girls not to enjoy sex. The findings are supported by DOM-CJPC (2008) who affirms that with sexual expression being problematic, many initiated girls who get married encounter marital relationship conflicts.

With respect to maternal health difficulties, thematic analysis of focus group discussions revealed that initiated girls presented issues with still births due to obstructed labour, difficulty in normal delivery, contraceptive difficulties like the use of intra uterine contraceptive devices and even infertility. Mwangi-Powell (1999) affirms that FGM causes numerous maternal complications which require specialized care. In particular, a certain participant noted, "I know of a woman who had been cut and her vagina opening sealed almost completely. This prevented her from having children of her own." Technically, midwives who are not familiar with FGM get alarmed when encountering a maternity case of an initiated girl for the first time. Thus, midwives need training exposure to deliveries involving initiated girls. 
The focus group discussions also brainstormed about bodily harm and infections related to FGM. Generally, immediate complications experienced after FGM were deliberated as including: haemorrhage, wound infection, pain, shock, injury to adjacent structures like the urethra, anal sphincter and vaginal walls, excessive bleeding and sometimes death occurred as a terminal consequence. One participant emphasized, "Death may occur due to haemorrhage because the cutting of the clitoris involves cutting across the clitoral artery whose blood flows at high pressure. Haemorrhage may also occur after the first week as a result of sloughing of the clot over the artery usually because of infection. If the bleeding is very severe and uncontrolled especially due to fear of seeking medical intervention, death becomes inevitable." Thus, the findings confirm that post FGM effects are severe and depend on the circumciser's age, eyesight and dexterity as well as the type of FGM procedures employed, the tools used and the struggle put up by the girl (WHO, 2006). Actually, HIVIAIDS infections were reported to have been caused by FGM among Ameru girls as reflected in the following excerpt, "It is sad to report that some of our Ameru girls have been infected with HIVIAIDS out of this FGM practice. This has been due to "sharing a knife" which was part of what enhanced the feeling of community membership or belongingness among initiates cut the same time. However, the rate of HIVIAIDS infection is declining as each girl carries a fresh blade for use during the FGM process for fear of infection." This may explain why the initiated girls affirmed that they were worried FGM would transmit HIVIAIDS and other sexually transmitted infections. The focus discussion group members concluded indeed the practice entails serious risks and other social harm

\section{Recommendations}

i. Primary health care facilities such as dispensaries and health centers should be equipped with essential physical and human resources to manage delivery complications akin to female genital mutilation victims who often require caesarian section as well as strong antibiotics to curb infections.

ii. $\quad$ There is need to strengthen the Ministry of Health through training the nurses and other medical personnel on proper handling of girls and women who have undergone FGM. Specifically, the training should address child deliveries and also incorporate counseling that will assist the medical personnel to address post FGM traumatic events.

iii. Guidance and counseling services related to female genital mutilation negative outcomes such as psychological trauma, distorted self concept, physical discomfort and specialized self care should be extended to victims.

\section{References}

Abor, A. P. (2006). Female Genital Mutilation: Psychological and Reproduction Health Consequences. The Case of Kayoro Traditional Area in Ghana. Journal of Gender and Behavior. Vol 4, No 1. P 659-684.

Abusharaf, R. M. (2000). 'Female Circumcision Goes Beyond Feminism': Anthropology News: March 2000. Boston: Allyn \& Bacon.

Barstow, W. (1998). The Consequences of Modernity. Stanford: California Stanford University Press.

DOM/CJPC. (2008). Alternative Rite of Passage for Girls in Meru: A Curriculum for Embracing Change for a Better Life. Paulines Publications. Nairobi.

Einstein, G. (2008). From Body to Brain: Considering the Neurobiological Effects of Female Genital Cutting. Perspect Biol Med, 51(1):8497.

Hansen, W. (1972). Infibulation: Female Genital Mutilation in Islamic North Eastern Africa. New Brunswick, NJ: Transaction.

Kanake, A. K. (2001). Change and Continuity in the Practice of Clitoridectomy: a case study Of the Tharaka of Meru-East District. Unpublished M.A dissertation, Kenyatta University.

Mwangi-Powell, F. (1999). The Switch Project: A FGM Related Study. London: Forward.

Njeru, E. \& PATH (2000). Female Circumcision in Nyeri, Embu and Machakos Districts of Kenya: Report on Key Informant Interventions. Nairobi, Kenya: PATH.

Nyangweso, M. (2001). Christ's Salvific Message and the Nandi ritual of female circumcision. Journal of Theological Studies. 63 (3).

Pillinger, J. (2007). The situation and experience of women migrant workers in Ireland. pp.42-47 Ink. Kolthof (Ed) Equal Rights, Equal voices: Migrant Women in European Union, 19 -21 January.

Toubia, N. (1994). Female Circumcision as a Public Health Issue. New England Journal of Medicine 331 R (12): $712-717$.

Toubia, N. (1999). Caring for Women with Circumcision, a Technical Manual for Healthcare Providers. New York, Rainbo.

Valderrama, J. (2002). 'Female Genital Mutilation: Why are we so Radical? In the Lancet, 39, pp.529 - 30.

Wabaki, W. (2007). African Battles to make Female Genital Mutilation History' in the Lancet 39, pp.1060 -1070.

Who, (1996). Female Genital Mutilation: Information Kit, Geneva, Dept of Women/s Health, Health Systems and Community Health,

Who, (2000). A Systematic Review of the Health Complications of Female Genital Mutilation including Sequence in Childbirth. Geneva, WHO. 
Who, (2006). Study group of female Genital Mutilation and Obstetric Outcomes. Banks E, Meirik O, Farlay T, Akande O, Bathja H et al. Female Genital Mutilation and Obstetric Outcome: WHO Collaborative Prospective Study in Six African Countries, Luncet 2006, 367 (9525)" 1835 - 1841. 